\title{
Use of Online Energy System Optimization Models
}

\author{
Diego Ruiz and Carlos Ruiz \\ Soteica Europe, S.L. \\ Spain
}

\section{Introduction}

Modern industrial facilities operate complex and inter-related power systems. They frequently combine internal utilities production with external suppliers, including direct fired boilers, electric power generation with turbo alternators or gas turbines, heat recovery steam generators, have different drivers (i.e., turbines or motors) for pumps or compressors and several types of fuels available to be used. Tighter and increasingly restrictive regulations related to emissions are also imposing constraints and adding complexity to their management. Deregulated electric and fuels markets with varying prices (seasonally or daily), contracted and emissions quotas add even more complexity. Production Department usually has the responsibility for the operation of the facility power system but, although Operators are instructed to minimize energy usage and usually tend to do it, a conflict often is faced as the main goal of Production is to maintain the factory output at the scheduled target. The power and utilities system is seen as a subsidiary provider of the utilities needed to accomplish with the production target, whichever it takes to generate it.

Big and complex industrial facilities like Refineries and Petrochemicals are becoming increasingly aware that power systems need to be optimally managed because any energy reduction that Operations accomplish in the producing Units could eventually be wasted if the overall power system cost is not properly managed. However, process engineers always attempted to develop some kind of tools, many times spreadsheet based, to improve the way utilities systems were operated. The main drawback of the earlier attempts was the lack of data: engineers spent the whole day at phone or visiting the control rooms to gather information from the Distributed Control System (DCS) data historian, process it at the spreadsheet and produce recommendations that, when ready to be applied, were outdated and not any more applicable.

The evolution from plant information scattered through many islands of automation to unified and centralized Plant Information Systems was a clear breakthrough for the process engineering work. The long term, facility wide Plant Information System based historians constitute what is known as an enabling technology, because they became the cornerstone from where to build many other applications. Besides others, advanced process control, optimal production programming, scheduling and real time optimization technologies were built over them and flourished after data was stored for long terms and became easily retrievable. 
Process engineers, still working on their original spreadsheets, attempted to improve the early days calculations by linking them to real time data and performing some sort of optimization. They used the internal optimizers or solvers provided with the spreadsheet software. One of the authors went though the same path when he was a young process engineer at a Petrochemical Complex. After many years of exposure to dozens of manufacturing sites worldwide, he found that almost all Process Engineering Departments had in use an internal spreadsheet over which several process engineers worked when on duty at the power house or utilities unit. The spreadsheets usually evolved wildly during many years and became extremely complex as hundreds of tags were added and, very often, they remained completely undocumented.

That kind of "internal tools" are in general fragile: it is very easy to severely harm one of such spreadsheets by simply adding or moving a line or column, up to the extent to become completely unusable. Plant Information Systems provided, from the very beginning, a way to link real time or historical data very easily into a spreadsheet but, as raw data is contaminated with unexpected problems, sometimes hard to identify and filter from errors, the use of such a tools for real time optimization was seldom a real success. We commonly found they were used for a while, usually requiring a lot of effort from the process engineer who developed it but, as soon as the creator was promoted or moved to other position, their use steeply declined and became an unused, legacy application. It was becoming more and more clear that a certain kind of intelligence should be added to those energy management tools in order to produce good results in a consistent way, dealing with real time information potential errors and maintained green and usable for long periods, with minimal engineering effort.

The authors found that, for the Process Industry, the definition of an intelligent system is generic and not very well defined. The industry usually call "intelligent" to any piece of software that helps to automate the decision making process, efficiently control a complex process, is able to predict properties of products or process variables, alerting or preventing hazardous situations or, in last instance, optimize process or business economics. For the practical engineers, the definition of an intelligent system is factual, not methodological. But always there is a computer behind, accessing data and running a piece of software. The above mentioned systems comply, up to certain extent, with one of the classical definitions of intelligence (Wiener, 1948): the intelligent behavior is a consequence of certain feedback mechanisms, based on the acquisition and processing of to accomplish with a certain objective. A coherent engineering environment providing all the needed tools into a single shell, starting with real time data acquisition and information validation, flexible and versatile modeling and simulation environment, robust mixed integer non linear optimization techniques, appropriate reporting tools, results historization and easily interpretation of the site wide optimization solution and constraints was a real need. Once available, energy systems became optimized and operated under an optimal perspective.

During the past 20 years, Visual MESA optimization software evolved from the earlier text based, offline application of the 1980's to an online, real time, graphical user interfaced, highly sophisticated intelligent system considered today as the industry standard Energy Management System (EMS) real time online optimizer (Nelson et al., 2000). Software development time line is presented in Fig.1, showing the main landmarks of the past years. It has been widely implemented in the processing industry and it is applied routinely to reduce the cost of operating the energy systems at power, 
chemical, petrochemical, and refinery plants worldwide. Several projects where the authors participated are cited in the References list below. A few of them will be also commented.

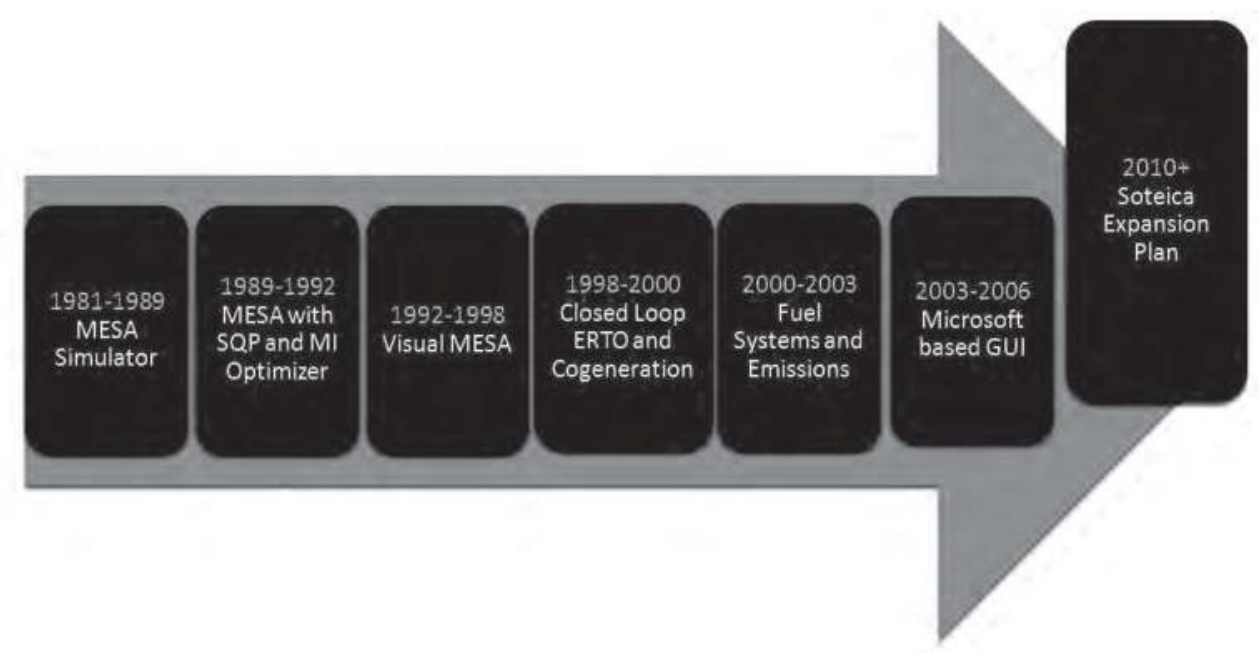

Fig. 1. Visual MESA Energy Management Software Development Time Line

\section{Energy management system description}

A detailed model of the energy system (fuels, steam, electricity, boiler feed water and condensates network) is built within the EMS environment and it is continuously fed with validated, real time data. It includes all the actual constraints of the site and decision variables for their operation. Optimization is configured to minimize the total energy cost. Continuous performance monitoring is also done, since the model writes back its results to the Real Time Data Base (Plant Information System). It also provides reliable data that helps to audit the energy productions and usages within the site energy system, and in that way wastes can be detected and eliminated. The model is also often used in standalone mode to perform case studies for economical evaluations of potential investments and for planning the operation of the energy system. Greenhouse emissions are also taken into account.

\subsection{Manual, open loop versus closed loop operation}

Although the Operators still need to close the loop manually and projects have proven to save substantial amounts of money, with very fast pay-back, even more economic benefits can be obtained if some of the manual optimization handles are automated under a closed loop scheme (Uztürk et al., 2006). Closed loop applications are expected to be increasingly popular during the next few years, to become in future the Closed Loop Energy Real Time Optimizers (CLERTO) a new standard.

There are several and important additional advantages of using EMS's for online, real time, closed loop optimization because it increases the benefits already obtained in open 
loop, especially when fuels and power prices are market driven and highly variable. Several implementations of this kind have already been done (Wellons et al., 1994; Uztürk et al., 2006).

It is important to emphasize the fact that a successful online optimization application is much more than just providing 'a model and an optimizer'. It also requires the project team provides real time online application implementation experience and particular software capabilities that, over the life of the project, prove to be crucial in deploying the online application properly. These software features automate its execution to close the loop, provide the necessary simple and robust operating interface and allow the user to maintain the model and application in the long term (i.e., evergreen model and sustainability of the installation).

\subsection{Online capabilities}

The online capabilities are a relevant portion of the software structure and key to a successful closed loop implementation. A proper software tool should provide standard features right out of the box. Therefore, it should not require any special task or project activity to enable the software to easily interact and cope with real time online data. The EMS based models are created from scratch acquiring and relying on real time online data. A standard OPC based (OLE for process control) protocol interface has been provided to perform a smooth and easy communication with the appropriate data sources, such as a distributed control system (DCS), a plant information system, a historian or a real time database. Sensor data is linked to the model simulation and optimization blocks by simply dragging and dropping the corresponding icons from the builder's palette and easily configuring the sensor object to protect the model from measurement errors and bad values through the extensive set of validation features provided. Fig. 2 shows an example of the configuration options in case of sensor data validation failure.

Properly designed software need to provide all the main features to implement online and closed loop optimization including:

- $\quad$ Sensor data easily tied to the model (drag and drop).

- Data validation, including advanced features such as disabling optimizers or constraints depending on the status of given critical variables.

- Steady state detection capabilities, based on a procedure using key variables' fast Fourier transform (FFT) based technique to identify main process variables steadiness.

- Online model tuning and adaptation, including the estimation of the current imbalances and maintaining them constant during the optimization stage.

- Control system interfaces for closed loop, online optimization, sending the decision variables set points back to the DCS via OPC.

- Closed loop model and control system reliability and feasibility checks (i.e., communications watchdog capabilities), to ensure the proper communication between the optimizer and DCS, via OPC.

Fig. 3 shows typical installation architecture for closed loop real time optimization, including the proper network security layers and devices, for example firewalls and demilitarized zones (DMZ) domains. 


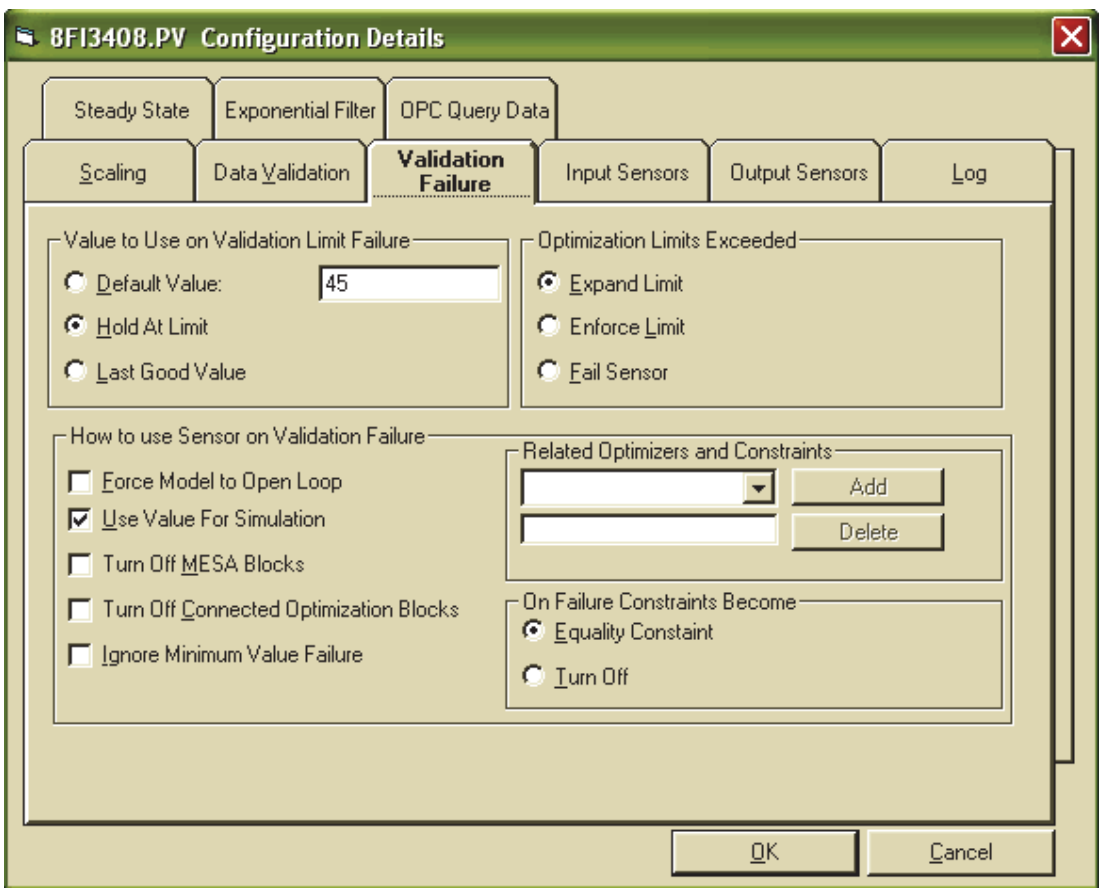

Fig. 2. Sensor Configuration Options

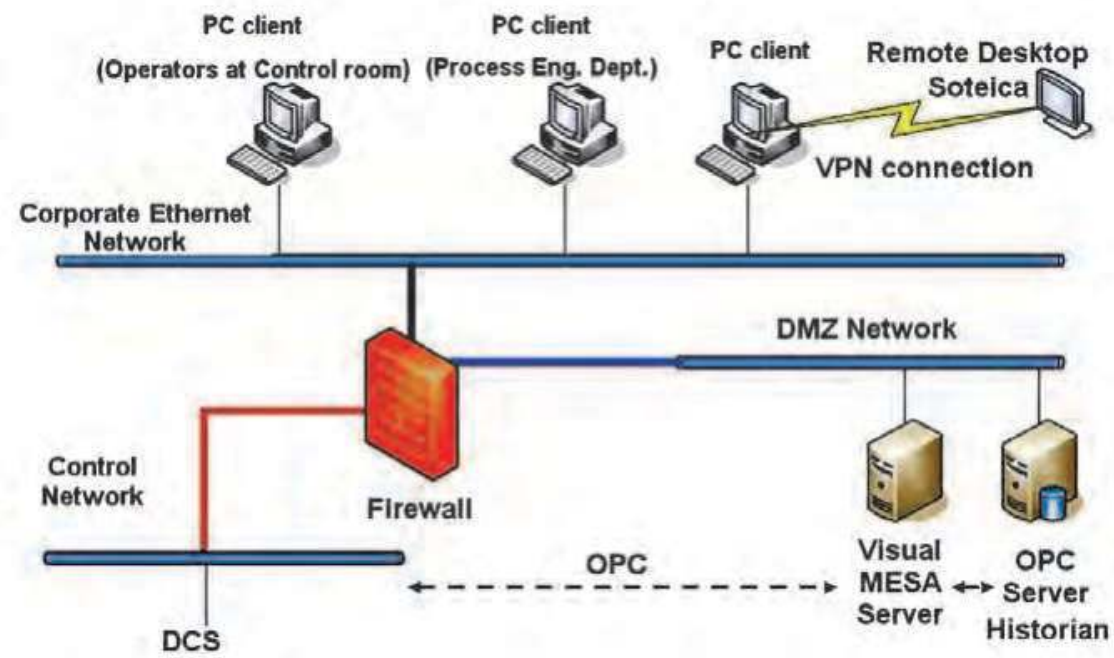

Fig. 3. Installation Architecture for Closed Loop Implementation 


\subsection{Optimization variables and constraints configuration for closed loop optimization}

Building a model that realistically represents the utilities and energy system topology, includes all the optimization variables and constraints and, at the same time, includes all the system economic details, especially the fuels and electricity contractual complexity.

Such a complex optimization problem can be represented and solved in a straightforward manner when using a proper software tool, even when the model is to be executed as a closed loop, real time application.

During the model and optimization building, the following set of variables must be identified and properly configured:

Optimization variables are those where some freedom exists regarding what value might be. For example, the steam production rate at which a particular boiler operates is a free choice as long as the total steam production is satisfied, thus the most efficient boiler's production can be maximized.

There are two main kinds of optimization variables that must be handled by an online energy management system optimizer:

- Continuous variables, such as steam production from a fired boiler, gas turbine supplemental firing and/or steam flow through a steam-driven turbo generator. Those variables can be automatically manipulated by the optimizer writing back over the proper DCS set points.

- Discrete variables, where the optimizer has to decide if a particular piece of equipment will operate or not. The most common occurrence of this kind of optimization is in refinery steam systems were spared pump optimization is available, one of the drivers being a steam turbine and the other an electric motor. Those variables cannot be automatically manipulated. They need the operator's manual action to be implemented.

Constrained variables are those variables that cannot be freely chosen by the optimiser but must be limited for practical operation.

There are two kinds of constraints to be handled:

- Direct equipment constraints. An example of a direct equipment constraint is a gas turbine generator power output. In a gas turbine generator, the fuel gas can be optimized within specified flow limits or equipment control devices constraints (for example, inlet guide vanes maximum opening angle). Also, the maximum power production will be constrained by the ambient temperature. Another example of a direct equipment constraint is a turbo generator power output. In a turbo generator you may optimize the steam flows through the generator within specified flow limits but there will also be a maximum power production limit.

- Abstract constraints. An abstract constraint is one where the variable is not directly measured in the system or a constraint that is not a function of a single piece of equipment. An example of this type of constraints is the scheduled electric power exported to the grid at a given time of the day. Economic penalties can be applied if an excess or a defect. Another example of this type of constraint is steam cushion (or excess steam production capacity). Steam cushion is a measure of the excess capacity in the system. If this kind of constraint were not utilized then an optimizer would recommend that the absolute minimum number of steam producers be operated. This is unsafe because the failure of one of the units could shutdown the entire facility. 


\section{Project activities}

An Energy Management System (EMS) Implementation project is executed in 9 to 12 months. The main steps are presented in Fig. 4. and discussed below.

\subsection{Required information}

After the Purchase Order is issued, a document would be submitted to the Site with all the informational requirements for the EMS project sent it to the project owner. By project owner we understand a Site engineer who, acting as a single interface, will provide the needed information and coordinate all the project steps. The EMS server machine would need to be configured with the required software, including the OPC connectivity server and made available prior to the Kick-Off Meeting.

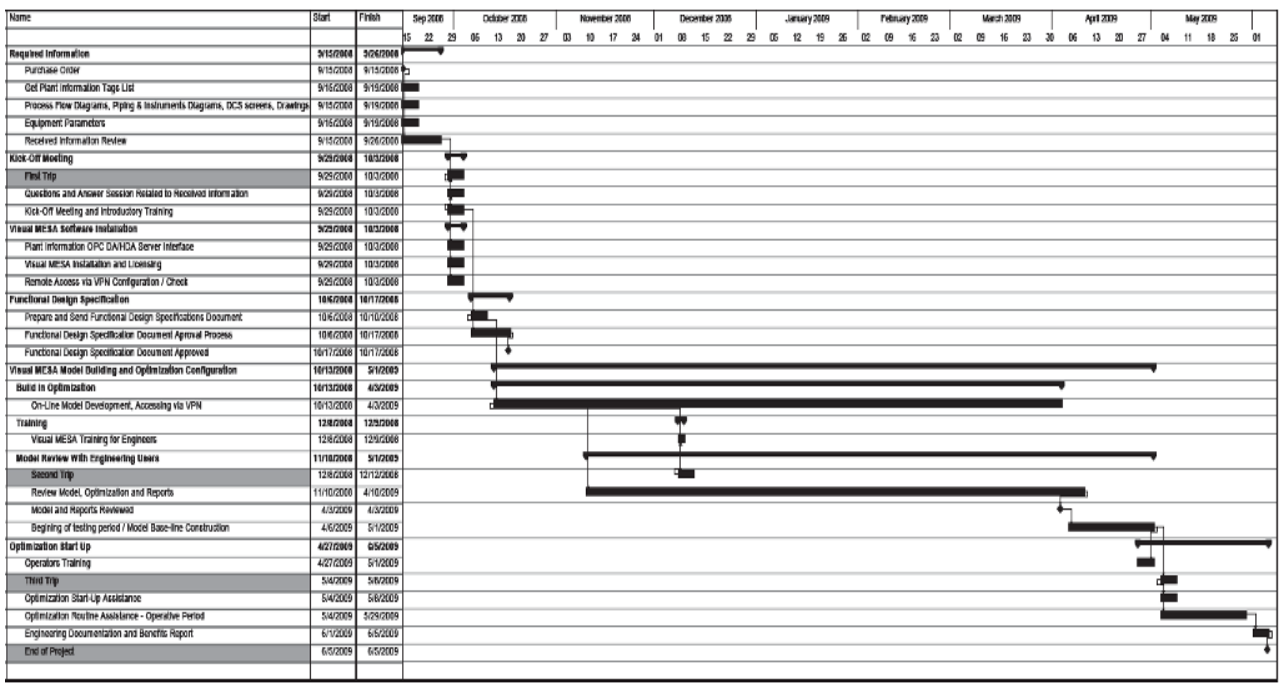

Fig. 4. Typical Energy Management System Implementation Project Schedule

\subsection{Kick-off meeting}

Prior to the Kick-Off Meeting, the provided information will be reviewed to have a better understanding of the Site facilities and process. Additional questions or clarifications would be sent to the Site regarding particular issues, as required. During the week of the on-site Kick-Off Meeting, all information would be reviewed with the Site staff, and additional information required for building the model would be requested, as needed. At that time, the optimization strategy would also be discussed. During the same trip, an introduction to the EMS will be given to the project owner in order for him to have a better understanding of the scope, information requirements and EMS modelling. The EMS software would be installed at this time. 


\subsection{EMS software installation}

The software is then configured and licensed on the EMS server PC. It would also be connected to the OPC server. Remote access to the model would also need to be made available at this time and would need to be available throughout the rest of the project.

\subsection{Functional design specification}

With the information provided during the Kick-Off meeting, a Functional Design Specification document would be prepared, revised by both parties in concert, and then approved by the Site. In this document, a clearly defined scope of the model and optimization is provided and will be the basis for the rest of the project work.

\subsection{Visual mesa model building and optimization configuration}

During this stage, the model and the report are built working remotely on the EMS server. The model grows with access to online real time data. Every time a new piece of equipment or tag is added, it can instantly begin to gather information from the Plant Information System via the OPC interface. Periodic questions and answers regarding the equipment, optimization variables, and constraints may be asked to the Site. The second trip to the facility would occur during this stage and would be used for mid-term review of the model and optimization. Also, an EMS training course for engineers is given at that time. Continuing forward, the model is continually reviewed by both parties and any improvements are made, as required. After reviewing the model and confirming that it meets the requirements of the Functional Design Specification, the Site would give its approval of the model.

Upon model approval, a month-long testing period would commence, the results of which would form the model "burn-in". During the "burn-in" period, the EMS would run routinely, but optimization recommendations would still not be implemented by the operations staff. A base line could be obtained based on the cost reduction predicted by the optimizer during this period, in order to compare with the full implementation of the suggestions at the end of the project. The project owner would review the optimization recommendations with the project developing staff. Minor modifications would be made to the model, as needed.

\subsection{Optimization startup}

Site engineers would then train the operations staff to use Visual MESA and to implement the recommendations. The trainers could use the provided training material as a basis for their training if they preferred. Continuing in this period, operations staff would begin implementation of the optimization recommendations. Project developing staff would return to the Site facility a third time to review implementation of the optimization recommendations and make any final adjustments to the model, as required. Throughout this stage, the model would be improved and adjusted according to feedback from Site staff. Lastly, engineering documentation specific to the Site implementation would be provided and a benefits report would be submitted, comparing the predicted savings before and after the optimum movements are applied on the utilities system. 


\section{Key Performance Indicators (KPIs)}

Besides the real time online optimization, during the EMS project appropriate energy performance metrics can also be identified and performance targets could be set. Also, within the EMS model calculation and reporting infrastructure, corrective actions in the event of deviations from target performance could be recommended.

Those metrics are usually known as Key Performance Indicators (KPI's) and can be related to:

- High level KPI's that monitor site performance and geared toward use by site and corporate management. For example: Total cost or the utilities system, predicted benefits, main steam headers imbalances, emissions, etc.

- Unit level KPI's that monitor individual unit performance and are geared toward use by unit management and technical specialists. For example: plant or area costs, boilers and heaters efficiencies, etc.

- Energy Influencing Variables (EIV's) that are geared towards use by operators. For example: Equipment specific operation parameters, like reflux rate, transfer line temperatures, cooling water temperature, etc.

The metrics are intended for use in a Site Monitoring and Targeting program where actual performance is tracked against targets in a timely manner, with deviations being prompting a corrective response that results in savings. They are calculated in the EMS and written back to the Plant Information System.

\section{Project examples}

The first two examples correspond to open loop implementations. The third one corresponds to a closed loop implementation. Finally, the last two examples correspond to very recent implementations.

\subsection{Example one}

In a French refinery a set of manual operating recommendations given by the optimizer during an operational Shift have been (Ruiz et al., 2007):

- Perform a few turbine/motors pump swaps.

- $\quad$ Change the fuels to the boilers (i.e., Fuel Gas and Fuel Oil).

As a result of the manual actions, the control system reacted and finally the following process variables:

- Steam production at boilers.

- Letdown and vent rates.

Figures 5, 6, 7 and 8 show the impact of the manually-applied optimization actions on steam production, fuel use and $\mathrm{CO}_{2}$ emissions reduction.

Obtained benefits can be summarized as follows:

- Almost 1 tons per hour less Fuel Oil consumed.

- Approx 7 tons per hour less high pressure steam produced.

- Approx 2 tons per hour less $\mathrm{CO}_{2}$ emitted.

- Approx $200 \mathrm{~kW}$ more electricity imported (which was the lowest cost energy available). 


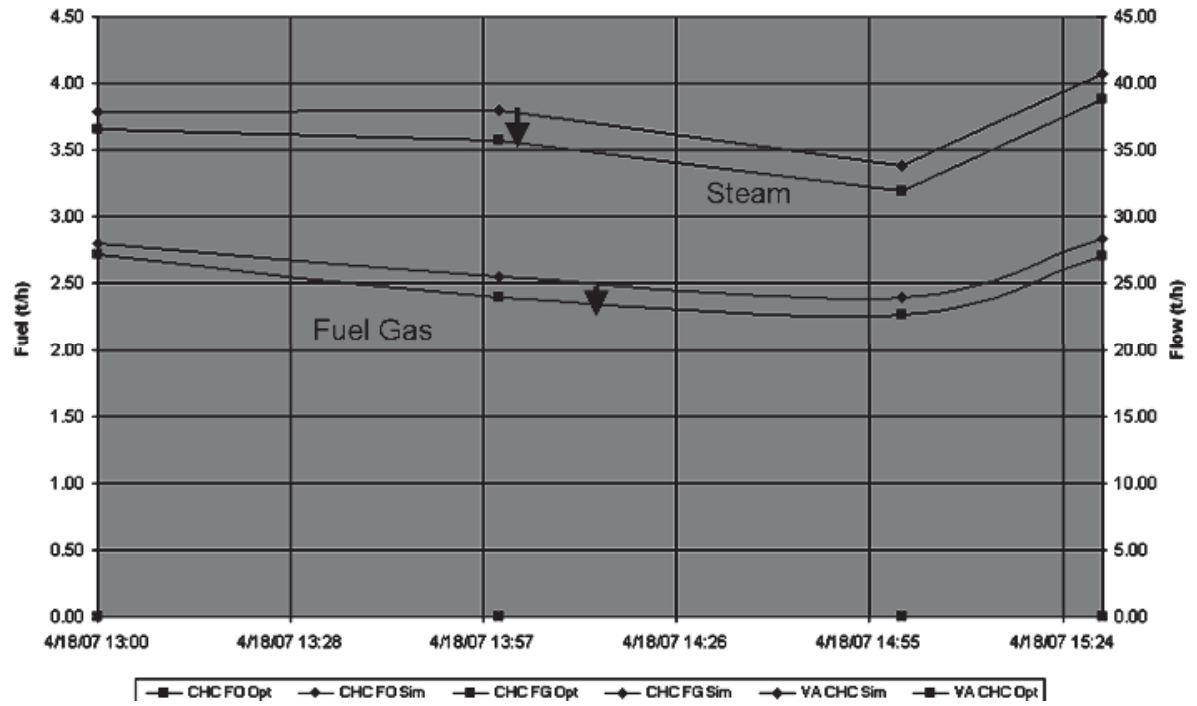

Fig. 5. Boiler C (100\% Fuel Gas); 2 tons per hour less of steam

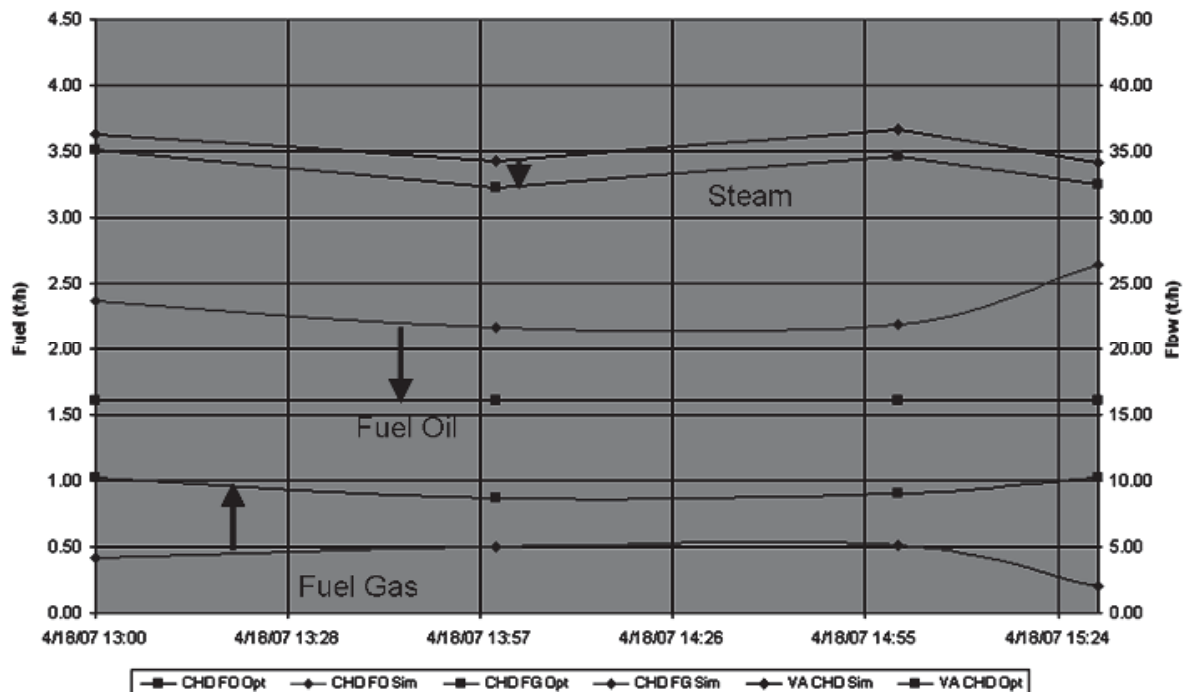

Fig. 6. Boiler D (Fuel Oil and Fuel Gas); 2 tons per hour less of steam and Fuel Oil sent to the minimum 


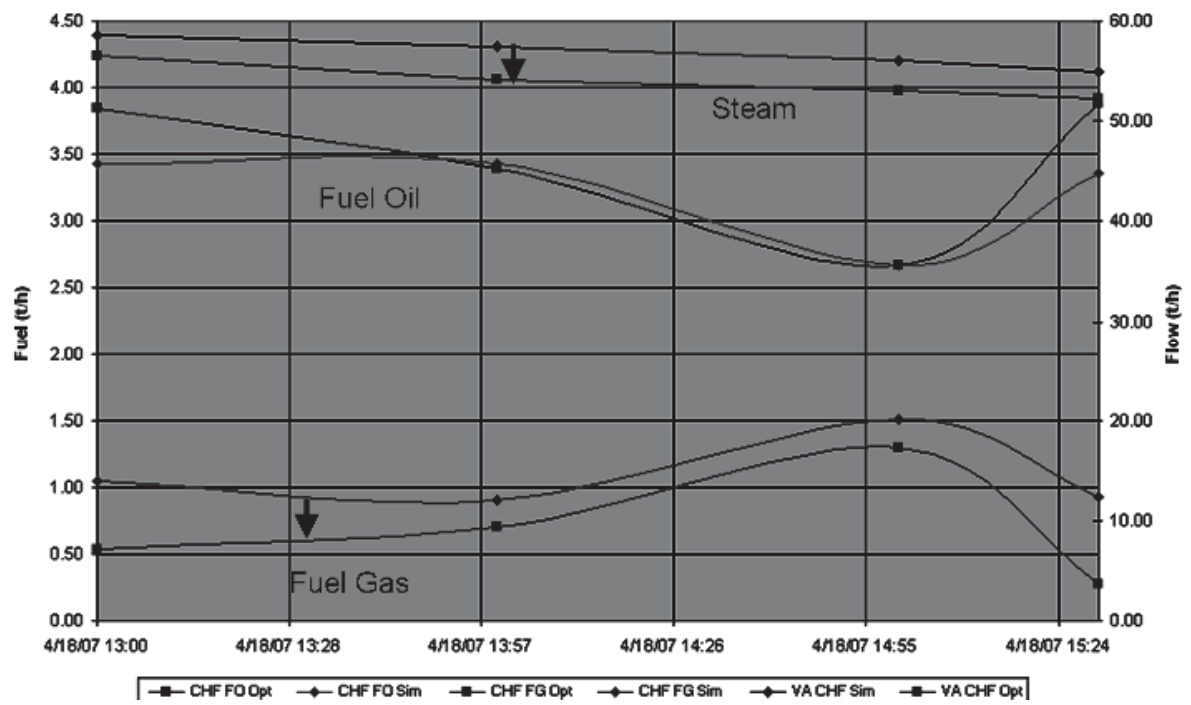

Fig. 7. Boiler F (Fuel Oil and Fuel Gas); more than 3 tons per hour less of steam

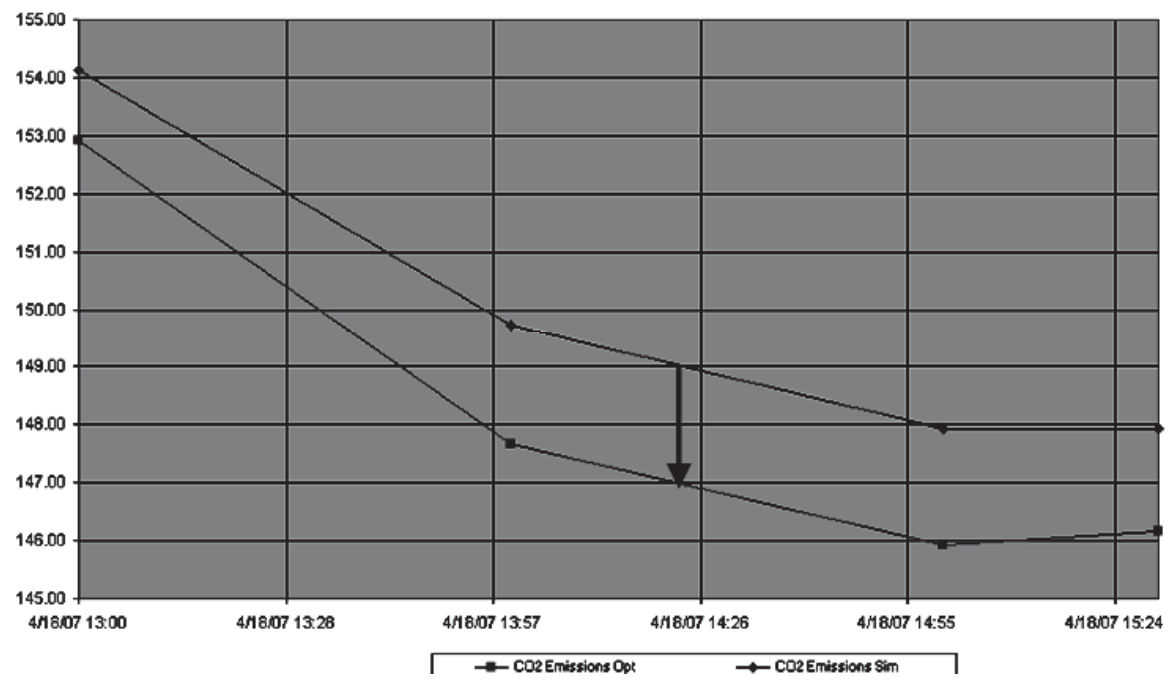

Fig. 8. $\mathrm{CO}_{2}$ emissions; 2 tons per hour less

\subsection{Example two}

The second example corresponds to the energy system of a Spanish refinery with an olefins unit (Ruiz et al., 2006). In order to accurately evaluate the economic benefits obtained with the use of this tool, the following real time test has been done: 
- $\quad$ First month: Base line, The EMS being executed online, predicting the potential benefits but no optimisation actions are taken.

- Second month: Operators trained and optimization suggestions are gradually implemented.

- Third month: Optimization recommendations are followed on a daily basis.

Fig. 9 shows the results of this test. Over that period, in 2003, $4 \%$ of the energy bill of the Site was reduced, with estimated savings of more than 2 million $€ /$ year.

\subsection{Example three}

The third example corresponds to a Dutch refinery where the EMS online optimization runs in closed loop, the so-called energy real time optimizer (Uztürk et al., 2006).

Typical optimisation handles include letdowns, load boilers steam flow, gas turbine generators/steam turbine generators power, natural gas intake, gas turbine heat recovery, steam generators duct firing, extraction of dual outlet turbines, deaerator pressure, motor/turbine switches, etc. Typical constraints are the steam balances at each pressure level, boiler firing capacities, fuel network constraints, refinery emissions (SO2, NOx, etc.) and contract constraints (for both fuel and electric power sell/purchase contracts).

Benefits are reported to come from the load allocation optimisation between boilers, optimised extraction/condensing ratio of the dual outlet turbines, optimised mix of discretionary fuel sales/purchase, optimised gas turbine power as a function of fuel and electricity purchase contract complexities (trade off between fuel contract verses electricity contract penalties).

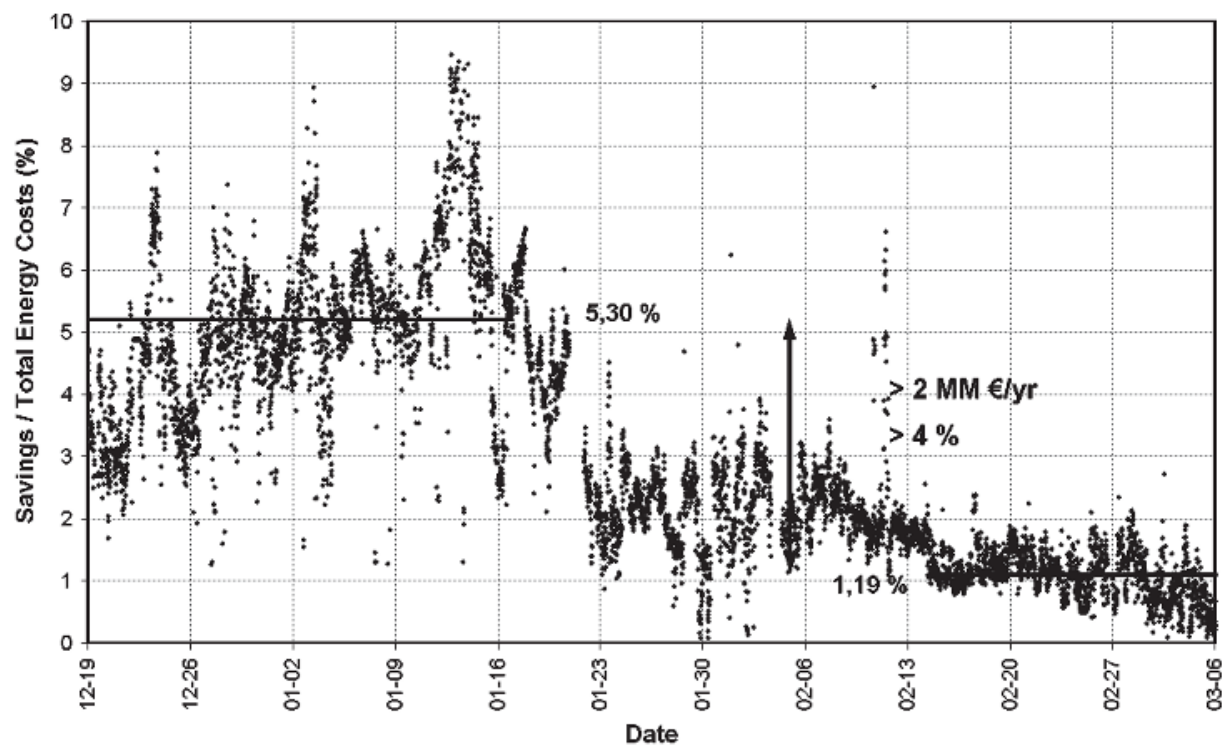

Fig. 9. Energy cost reduction evolution by using an online energy management tool 


\subsection{Example four}

The fourth example corresponds to a French petrochemical complex, where the energy management system helps in emissions management too (Caudron, et al, 2010).

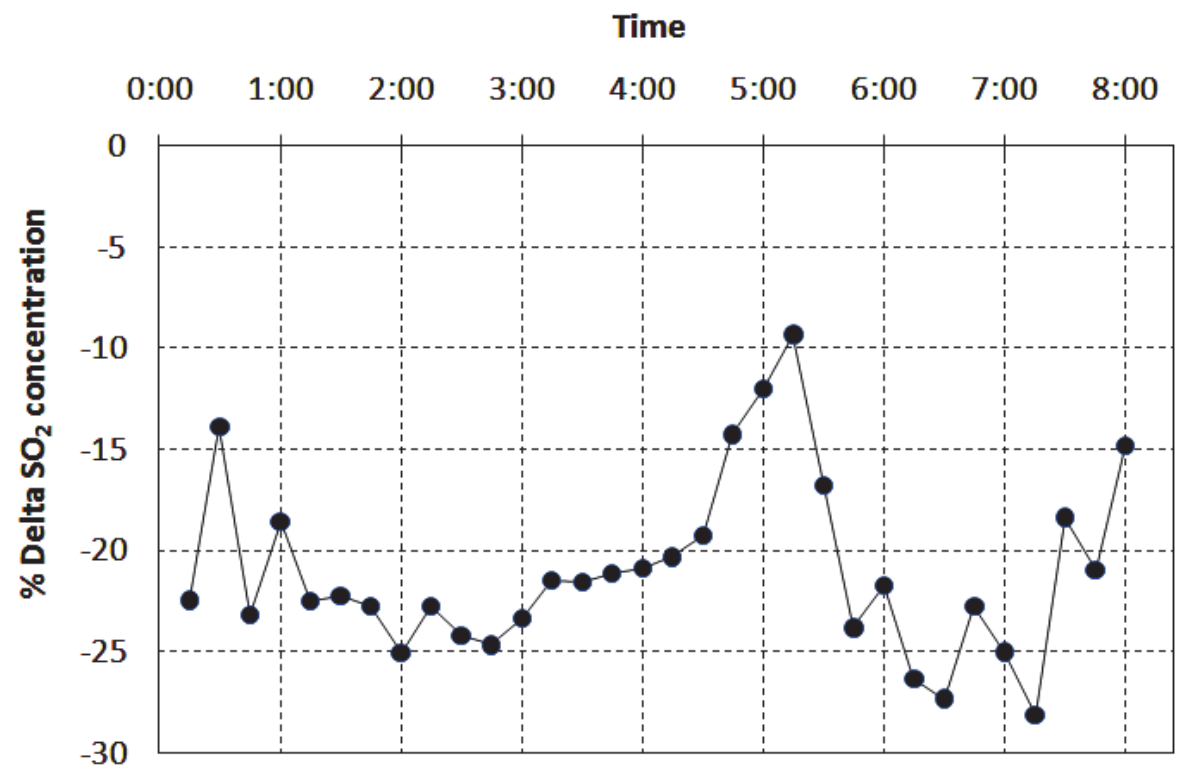

Fig. 10. Identified $\mathrm{SO}_{2}$ emissions reduction along a shift

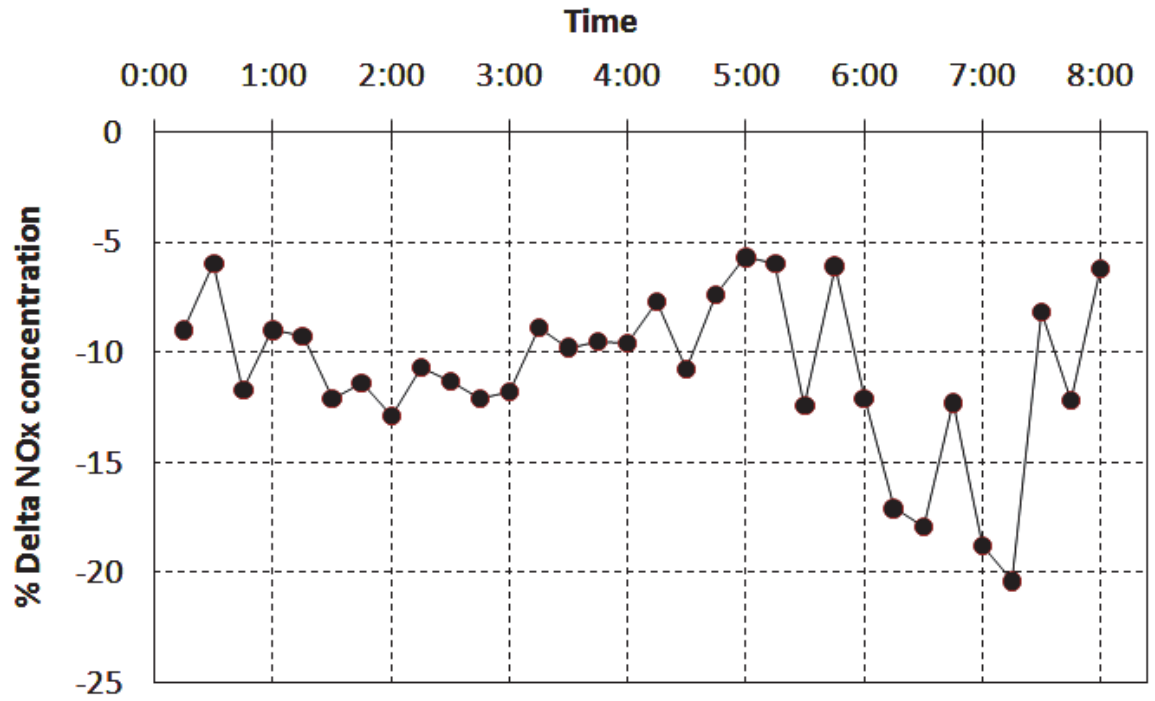

Fig. 11. Identified $\mathrm{NO}_{\mathrm{x}}$ emissions reduction along a shift 
While reducing the energy costs, Figures 10 and 11 show respectively an example of the corresponding potential reduction in $\mathrm{SO} 2$ and $\mathrm{NOx}$ emissions (in terms of concentration with data corresponding to one of the main stacks) found during the same operational shift period applying the optimization recommendations. In this example, due to fuel management, a reduction in SO2 (around 20\% less in concentration) and in NOx (around $10 \%$ less in concentration) in one of the main stacks has been also obtained.

\subsection{Example five}

This last example corresponds to the implementation of the energy management system in a Polish refinery (Majchrowicz et al, 2010). Visual MESA historizes important key performance indicators (KPIs). The most important ones are the economic energy operating cost, the optimized one and the predicted savings. Figure 12 shows an example of potential savings reduction due to the application of optimizer recommendations meaning effective energy costs reduction achieved. Each point in the figure corresponds to an automatic Visual MESA run. The variability along some days in the predicted savings can have different reasons, such as the changes in the operating conditions (e.g. weather, changes in producers and consumers). When a set of recommendations are followed by operators on day to day basis based on site wide optimization, the predicted savings are closer to zero.

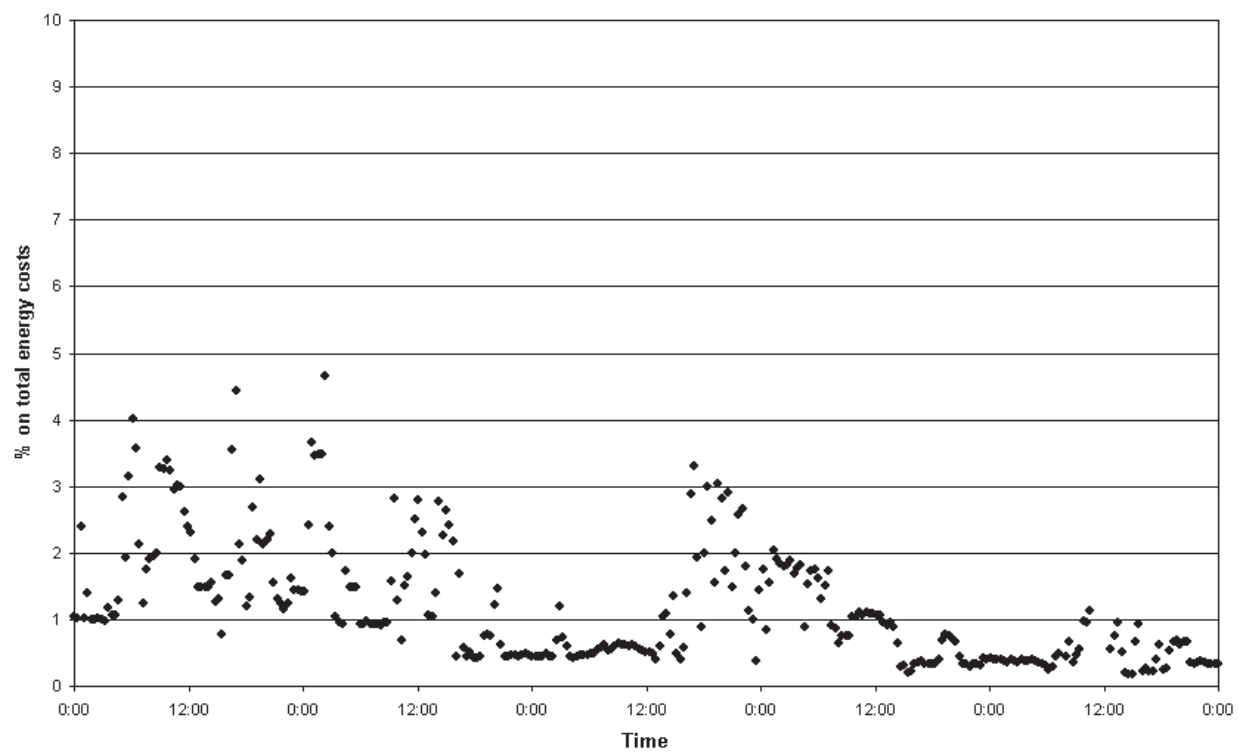

Fig. 12. Example of energy costs reduction follow-up

\section{Conclusion}

Online energy system optimization models are being used successfully throughout the Processing Industry, helping them to identify and capture significant energy cost savings. Although wide opportunities still exist for a growing number of real time online Energy Management Systems executed in open loop, an increased number of Closed Loop 
applications are expected in the near future. This evolution will bring additional economic benefits to the existing user base, especially when fuels and power prices are market-driven and highly variable. High frequency optimization opportunities that cannot be practically addressed by manual operating procedures would be captured and materialized. Of critical importance is having a robust and mature solver that reliably converges in a reasonable period of time in order to ensure buy-in from Operations for the continuous use of the system. More focus will be also on key process side operations, when tightly related with the Energy Network. Besides the Refining and Petrochemical industries, who were the early adopters of this kind of technology, other industries will take advantage of the real time energy management. For example, the Alcohol and Pulp \& Paper industries, where waste fuel boilers, electric power cogeneration and evaporators systems could be also optimized together and District Heating and Cooling companies (i.e., power houses which are providers of heating and cooling services to cities, towns, campuses, etc.), that produce steam, chilled water and many times include cogeneration of electricity.

\section{References}

Benedicto, S.; Garrote, B.; Ruiz, D.; Mamprin, J. \& Ruiz, C. (2007). Online energy management, Petroleum Technology Quarterly (PTQ), Q1 (January 2007), pp. 131-138.

Caudron, M.; Mathieu, J.; Ruiz, D.; Ruiz, C. \& Serralunga, F. (2010). Energy and emissions management at Naphtachimie petrochemical site. ERTC Energy Efficiency Conference 2010, Amsterdam, Netherlands.

García Casas, J.; Kihn, M.; Ruiz, D. \& Ruiz, C. (2007). The Use of an On-line model for Energy Site-Wide Costs Minimisation. European Refining Technology Conference (ERTC) Asset Maximisation Conference, Rome, Italy.

Kihn, M.; Ruiz, D.; Ruiz, C. \& García Nogales, A. (2008). Online Energy Costs Optimizer at Petrochemical Plant. Hydrocarbon Engineering, Vol. 13, No. 5, (May 2008), pp. 119123, ISSN 1468-9340

Majchrowicz, J.; Herra M.; Serralunga, F. \& Ruiz, D (2010). Online energy management at Grupa LOTOS refinery. ERTC Annual Meeting 2010, Istambul, Turkey.

Nelson, D.; Roseme, G. \& Delk, S. (2000). Using Visual MESA to Optimize Refinery Steam Systems, AIChE Spring Meeting, Session T9013, Georgia, USA

Reid, M.; Harper, C. \& Hayes, C. (2008). Finding Benefits by Modeling and Optimizing Steam and Power System. Industrial Energy Technology Conference (IETC), New Orleans, USA

Ruiz, D.; Ruiz, C.; Mamprin, J. \& Depto. de Energías y Efluentes Petronor (2005). Auditing and control of energy costs in a large refinery by using an on line tool, European Refining Technology Conference (ERTC) Asset Maximisation, Budapest, Hungary

Ruiz, D.; Ruiz, C.; Nelson, D.; Roseme, G.; Lázaro, M. \& Sartaguda, M. (2006), Reducing refinery energy costs, Petroleum Technology Quarterly (PTQ), Vol. Q1 (January 2006), pp. 103-105.

Ruiz, D.; Mamprin, J.; Ruiz, C. \& Département Procédés - Energie, Logistique, Utilités, TOTAL - Raffinerie de Feyzin (2007). Site-Wide Energy Costs Reduction at TOTAL Feyzin Refinery. European Refining Technology Conference (ERTC) 12th Annual Meeting, Barcelona, Spain.

Ruiz, D.; Ruiz, C. \& Nelson, D. (2007). Online Energy Management. Hydrocarbon Engineering, Vol. 12, No. 9, (September 2007), pp. 60-68, ISSN 1468-9340 
Ruiz, D. \& Ruiz, C. (2008). A Watchdog System for Energy Efficiency and CO2 Emissions Reduction. European Refining Technology Conference (ERTC) Sustainable Refining, Brussels, Belgium

Ruiz, D. \& Ruiz,C. (2008). Closed Loop Energy Real Time Optimizers. European Refining Technology Conference (ERTC) Annual Meeting Energy Workshop, Vienna, Austria

Uztürk, D.; Franklin, H.; Righi, J. \& Georgiou, A. (2006). Energy System Real Time Optimization. NPRA Plant Automation and Decision Support Conference, Phoenix, USA.

Wellons, M.; Sapre, A.; Chang, A. \& Laird, T. (1994). On-line Power Plant Optimization Improves Texas Refiner's Bottom Line. Oil \& Gas Journal, Vol.22, No.20, (May 1994)

Wiener N. (1948). Cybernetics, Control and Communication in the Animal and the Machine (second edition), MIT Press, Cambridge, Mass. 


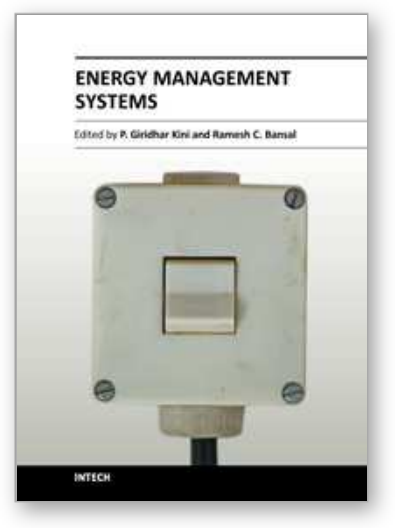

\author{
Energy Management Systems \\ Edited by Dr Giridhar Kini
}

ISBN 978-953-307-579-2

Hard cover, 274 pages

Publisher InTech

Published online 01, August, 2011

Published in print edition August, 2011

This book comprises of 13 chapters and is written by experts from industries, and academics from countries such as USA, Canada, Germany, India, Australia, Spain, Italy, Japan, Slovenia, Malaysia, Mexico, etc. This book covers many important aspects of energy management, forecasting, optimization methods and their applications in selected industrial, residential, generation system. This book also captures important aspects of smart grid and photovoltaic system. Some of the key features of books are as follows: Energy management methodology in industrial plant with a case study; Online energy system optimization modelling; Energy optimization case study; Energy demand analysis and forecast; Energy management in intelligent buildings; PV array energy yield case study of Slovenia;Optimal design of cooling water systems; Supercapacitor design methodology for transportation; Locomotive tractive energy resources management; Smart grid and dynamic power management.

\title{
How to reference
}

In order to correctly reference this scholarly work, feel free to copy and paste the following:

Diego Ruiz and Carlos Ruiz (2011). Use of Online Energy System Optimization Models, Energy Management Systems, Dr Giridhar Kini (Ed.), ISBN: 978-953-307-579-2, InTech, Available from:

http://www.intechopen.com/books/energy-management-systems/use-of-online-energy-system-optimizationmodels

\section{INTECH}

open science | open minds

\author{
InTech Europe \\ University Campus STeP Ri \\ Slavka Krautzeka 83/A \\ 51000 Rijeka, Croatia \\ Phone: +385 (51) 770447 \\ Fax: +385 (51) 686166 \\ www.intechopen.com
}

\author{
InTech China \\ Unit 405, Office Block, Hotel Equatorial Shanghai \\ No.65, Yan An Road (West), Shanghai, 200040, China \\ 中国上海市延安西路65号上海国际贵都大饭店办公楼 405 单元 \\ Phone: +86-21-62489820 \\ Fax: $+86-21-62489821$
}


(C) 2011 The Author(s). Licensee IntechOpen. This chapter is distributed under the terms of the Creative Commons Attribution-NonCommercialShareAlike-3.0 License, which permits use, distribution and reproduction for non-commercial purposes, provided the original is properly cited and derivative works building on this content are distributed under the same license. 